\title{
Políticas Públicas Educacionais para efetivação da educação de jovens e adultos no Paraná
}

\author{
Educational Public Policies for the effectiveness of education of \\ youth and adults in Brazil
}

Fabrício Veiga Costa

Ivan Dias da Motta ${ }^{2}$

Andréia Cristina dos Santos Honorato de Almeida ${ }^{3}$

\begin{abstract}
RESUMO:
O presente artigo cientifico objetiva investigar os fundamentos jurídico-legais utilizados no âmbito federal e do Estado do Paraná para assegurar o planejamento, execução e efetividade da política pública educacional de formação escolar de jovens e adultos. A escolha do tema se justifica em razão de sua relevância teórica, prática, jurídica, social e política, haja vista que por meio da referida política pública torna-se viável assegurar a inclusão, emancipação e condições para o exercício da cidadania de jovens e adultos. Por meio da implementação da política pública de educação para jovens e adultos o Estado do Paraná evidenciou uma história de exclusão de milhões de sujeitos que foram preteridos de usufruir o direito de fazerem parte do sistema educacional e revelaram uma queda significativa do analfabetismo na população de 15 anos ou mais. No Brasil há aproximadamente 12 milhões de pessoas excluídas do acesso às letras e a outros bens sociais, ressaltando-se o compromisso de incluí-las no universo da cidadania, com base nos compromissos políticos previstos e discutidos nas várias Declarações e Fóruns Mundiais dos quais é signatário. Por meio da pesquisa bibliográfica e documental foi
\end{abstract}

\footnotetext{
${ }^{1}$ Pós-doutorado em Educação (UFMG/2015). Doutorado e Mestrado em Direito Processual (PUCMINAS). Graduação em Direito pela Universidade Federal de Uberlândia (2001 Professor da Pós-Graduação Stricto Sensu em Proteção dos Direitos Fundamentais e da Graduação em Direito da Universidade de Itaúna. Coordenador do Curso de Especialização em Direito Processual Constitucional da Faculdade de Pará de Minas. Coordenador do curso de Especialização em Direito Processual Civil na Fundação Pedro Leopoldo. Professor da Graduação em Direito na Faculdade de Pará de Minas, Faculdade Pedro Leopoldo, FAMINAS-BH e FASASETE - Faculdade Santo Agostinho de Sete Lagoas. Professor da Especialização em Direito Processual e Direito Público do IECPUCMINAS. Professor da PUCMINAS (Virtual). Área de Atuação: Direito Processual Civil, Direito Civil e, especialmente, Direito de Família; Direito Educacional; Direitos Homoafetivos.

${ }^{2}$ Graduação em Direito pela Universidade Estadual de Maringá (1996), Mestrado em Direito das Relações Sociais pela Pontifícia Universidade Católica de São Paulo (1998) e Doutorado em Direito das Relações Sociais pela Pontifícia Universidade Católica de São Paulo (2000). Pós-doutorado em Direito Educacional pela Pontifícia Universidade Católica de São Paulo (2001). Professor permanente do Programa de Mestrado em Direito do Centro Universitário de Maringá, integrando a linha de pesquisa "A Tutela Constitucional e Privada dos Direitos da Personalidade nas Relações Privadas". Atuação profissional na área da advocacia e consultoria em Direito Educacional.

${ }^{3}$ Mestre em Ciências Jurídica pela UNICESUMAR - Centro Universitário de Maringá (2017), Especialização em Educação Especial: Atendimento às Necessidades Especiais pelo ESAP-Instituto de Estudos Avançados e Pós Graduação (2006) e Educação de Jovens e Adultos na Faculdade Eficaz(2014), Graduação em Ciências pela Fundação Faculdade de Filosofia, Ciências e Letras de Mandaguari (1999), em Pedagogia pela Faculdade de Filosofia, Ciências e Letras de Mandaguari (2002) e Direito pela UNICESUMAR - Centro Universitário de Maringá (2015). Professora do Ensino Fundamental - Series Iniciais na Rede Municipal de Maringá.
} 
possível construir análises quantitativas, qualitativas, temáticas, teóricas, históricas, interpretativas e comparativas, de modo a evidenciar sob o ponto de vista crítico que a política pública de educação de jovens e adultos no Paraná viabilizou a formação cidadã, preparação para o mercado de trabalho e o pleno desenvolvimento das pessoas que atuaram como protagonistas.

\title{
Palavras-Chaves:
}

Educação de Jovens e Adultos; Políticas Públicas; Direito à Educação.

\begin{abstract}
:
This scientific article aims to investigate the juridical and legal foundations used in the federal and Paraná State to ensure the planning, execution and effectiveness of public educational policy for school education of young people and adults. The choice of theme is justified by its theoretical, practical, legal, social and political relevance, given that through this public policy it becomes feasible to ensure the inclusion, emancipation and conditions for the exercise of citizenship of young people and adults. Through the implementation of public education policy for youth and adults, the State of Paraná evidenced a history of exclusion of millions of subjects who were deprived of the right to be part of the educational system and revealed a significant drop in illiteracy among the population of 15 years or more. In Brazil there are approximately 12 million people excluded from access to letters and other social goods, with a commitment to include them in the universe of citizenship, based on the political commitments foreseen and discussed in the various Declarations and World Forums of which it is signatory. Through bibliographic and documentary research it was possible to construct quantitative, qualitative, thematic, theoretical, historical, interpretive and comparative analyzes, in order to show from a critical point of view that the public policy of youth and adult education in Paraná enabled the formation citizenship, preparation for the labor market and the full development of the people who acted as protagonists.
\end{abstract}

Keywords: Youth and Adult Education; Public policy; Right to education.

\section{INTRODUÇÃO}

O objetivo geral da presente pesquisa cientifica é investigar a proposição e implementação de políticas públicas educacionais para a efetivação da educação para jovens e adultos no Brasil. O estudo em tela delimitou seu objeto de análise no Estado do Paraná, momento em que foram construídas análises comparativas e qualitativas, visando o estudo específico e sistemático da problemática jurídica proposta. A escolha do tema justifica-se em razão de sua relevância teórica e prática, especialmente sob o aspecto da importância de fomentar o debate cientifico sobre o direito à educação de jovens e adultos, como proposta hábil 
a legitimar o exercício do direito à cidadania, pleno desenvolvimento da pessoa humana e preparação para o mercado de trabalho, tal como proposto pelas diretrizes constitucionais vigentes.

Visando sistematizar a abordagem do tema proposto, inicialmente foi desenvolvido um estudo sobre as políticas públicas para a educação de jovens e adultos no Brasil. Essa primeira abordagem justificou-se em virtude da importância de compreender os fundamentos utilizados pelo Estado no que atine a implementação da referida política pública educacional no âmbito nacional. Visando delimitar o espectro da análise proposta, por meio de pesquisa bibliográfica e documental foram investigados os parâmetros e fundamentos utilizados pelo Estado do Paraná no que atine à implementação da política pública voltada à educação de jovens e adultos, construindo-se, assim, um estudo comparativo e analítico com a proposta nacional referente à mesma temática posta ao debate cientifico.

Objetivando apresentar apontamentos e análises críticas contextualizadas do referido tema, desenvolveu-se análise qualitativa para o entendimento dos reflexos da educação de jovens e adultos no que diz respeito à formação cidadã, pleno desenvolvimento da pessoa humana e sua preparação para o mercado de trabalho. Por isso, foi esclarecido que a educação de jovens e adultos teve início no Brasil somente a partir da segunda metade do século XX, com novos pensamentos pedagógicos que consolidam políticas públicas para a EJA, já que esta modalidade de ensino nunca foi preocupação dos governantes e dirigentes do país. Nesse contexto de transformações políticas, econômicas e sociais surgem condições favoráveis à implantação de políticas públicas para a educação de jovens e adultos, que ganha destaque internacional com a UNESCO. Assim, o Estado aumenta as suas atribuições e as responsabilidades para com a educação de jovens e adultos, em resposta aos movimentos populares e as deliberações da UNESCO com relação ao analfabetismo e os altos índices de pessoas que não tinham acesso à educação.

Importante mencionar o pensamento pedagógico voltado para educação de jovens e adultos surge no ano de 1958, com a realização do Congresso Nacional de Educação de Adultos no Rio de Janeiro, momento em que foi priorizada a difusão do pensamento de Paulo Freire, que marca um novo período na educação de adultos no Brasil. Com a finalidade de se buscar metodologias eficazes e inovações nesse campo, foi reintroduzida a reflexão sobre o social no 
pensamento pedagógico, momento que surgiu o reconhecimento das características próprias dessa modalidade de ensino, porém com uma forte relação com a educação popular (HADDAD; DI PIERRO, 2000, p. 113).

Desde o início do processo de escolarização no Brasil a preocupação era com a instrução das crianças, ressaltando-se que tal pensamento começa a mudar a partir do início do processo de industrialização e aceleração da urbanização no país, já que os índices de analfabetismo eram altos e o nível de escolarização precária, equiparados aos demais países periféricos (NASCIMENTO, 2011, p. 7686). Nesse sentido, a educação popular surge das pressões de empresários, que vislumbraram a importância e as vantagens econômicas na alfabetização dos trabalhadores. A educação popular, sistematizada nas redes de ensino público no Brasil, teve como finalidade imediata o combate ao analfabetismo, destacando-se o fortalecimento do referido movimento educacional na década de 20 do século XX, visto que tal movimento ocorre com base nas grandes transformações da sociedade brasileira, associado ao processo de industrialização e a concentração populacional em centros urbanos, motivado pelos interesses financeiros das classes dominantes.

A delimitação do objeto de pesquisa se deu a partir do seguinte questionamento: a legislação federal, constitucional e do Estado do Paraná foram efetivadas de modo a assegurar a implementação de política pública educacional para jovens e adultos, que garanta o exercício da cidadania, pleno desenvolvimento da pessoa humana e preparação para o mercado de trabalho?

Por meio de pesquisa bibliográfica e documental, foi possível debater, problematizar e compreender de forma sistemática a política pública de educação de jovens e adultos, delimitando-se o objeto de análise no estudo comparativo das proposições nacionais e no Estado do Paraná no que atine a presente temática ora posta em discussão. A utilização do método dedutivo viabilizou a delimitação do objeto da pesquisa, partindo-se de uma concepção macroanalítica, qual seja, o estudo do direito à educação de jovens e adultos, recortando-se o estudo proposto no âmbito do Estado do Paraná. A construção de análises quantitativas, qualitativas, temáticas, teóricas e interpretativas viabilizou o estudo crítico do tema apresentado, identificando-se aporias hábeis ao desenvolvimento de outros estudos científicos. 


\section{POlíticas públicas para EduCaÇão de JOVEnS E Adultos No BRASIL}

O estudo histórico-legislativo das proposições legais voltadas especificamente para a regulamentação da educação de jovens e adultos no Brasil é recente, considerando-se que a implementação do referido direito somente passou a ser prioridade para o Estado no momento em que se verificou a indispensabilidade de preparação de pessoas para retroalimentar o sistema capitalista de produção. Tal premissa deixa evidente que a finalidade do Estado não é priorizar a formação cidadã e crítica de jovens e adultos a partir de uma instrução técnico-escolar. A implementação da política pública de educação de jovens e adultos somente passou a ser prioridade estatal no momento em que se verificou a necessidade da formação escolar na qualificação da mão de obra a ser disponibilizada para o mercado de trabalho.

Com o advento da Lei de Diretrizes e Bases da Educação Nacional - LDB a educação de jovens e adultos - EJA passa a ser concebida como uma modalidade formal da educação básica, conferindo-lhe uma dimensão diferenciada, objetivando-se possibilitar a superação da concepção de oferta aligeirada, compensatória e supletiva de escolarização. Em consonância com a Constituição Federal, a LDB estabelece no seu art. 37 que "a educação de jovens e adultos será destinada àqueles que não tiveram acesso ou continuidade de estudos no ensino fundamental e médio na idade própria” (BRASIL, Lei 9394, 1996).

A LDB assume a educação básica como política pública no sistema nacional de ensino e a EJA deixa de ser considerada como projeto de governo, ou ações pontuais de alfabetização e elevação de escolaridade, principalmente de ensino fundamental, para promover o pleno desenvolvimento da pessoa humana consagrado na Constituição. Com a consolidação dos princípios legais postulados pela Constituição, a LDB deu visibilidade para o início de discussões sobre como pensar formas de garantir direitos já conquistados, identificar o papel da educação em cenários políticos e históricos, além de refletir sobre a diversidade desses sujeitos participantes da EJA (HADDAD; DI PIERRO, 2000, p. 127).

A partir da LDB o Brasil vivencia um momento de intensa mobilização em torno da discussão do sentido da EJA como modalidade da educação básica, resultando, no ano de 2000, 
na aprovação das Diretrizes Curriculares Nacionais para a educação de jovens e adultos, por meio da Resolução CNE/CEB nº 01/2000 que, no parecer CNE/CEB nº11/2000 manifesta o reconhecimento por parte do Conselho Nacional de Educação - CNE da concepção de EJA como "um modo de existir com característica própria", devendo o seu desenvolvimento considerar "as situações, os perfis dos estudantes, as faixas etárias" e se pautar "pelos princípios de equidade, diferença e proporcionalidade na apropriação e contextualização das diretrizes curriculares nacionais e na proposição de um modelo pedagógico próprio, com fundamento no art. 205 da Constituição Federal que define que a educação é direito de todos (JULIÃO, FERRARI, 2017, p. 44).

Após dez anos da publicação das Diretrizes Curriculares supramencionadas foram instituídas, em 2010, as Diretrizes Operacionais para a Educação de Jovens e Adultos (Resolução CNE/CEB no 03/2010 - BRASIL, 2010), normatizando os aspectos relativos à duração dos cursos e idade mínima para ingresso na EJA, os exames de avaliação do desempenho dos estudantes, a certificação nos exames de EJA e a educação de jovens e adultos desenvolvida por meio da educação à distância (BRASIL, 2000, p. 1).

Importante ressaltar que a LDB incluiu, pela primeira vez na história das legislações educacionais, um capítulo destinado à EJA, então chamada de ensino supletivo, estabelecendo no artigo 24 a função de suprir a escolarização regular para adolescentes e adultos que não a tenham seguido ou concluído na idade certa. Nesse período foram criados os centros de estudos supletivos em todos os Estados brasileiros, com a proposta de serem modelo de educação do futuro, atendendo às necessidades de uma sociedade em processo de modernização, porém não atingiram seus objetivos, pois não receberam o apoio político nem os recursos financeiros suficientes para sua plena realização, atendendo aos interesses das empresas privadas de educação (VIEIRA, 2009, p. 9).

A organização da escola de $1^{\circ}$ grau estava centrada para o trabalho numa relação implícita e indireta e que, "[...] no segundo grau, a relação entre educação e trabalho, entre conhecimento e a atividade prática deverá ser tratada de maneira explicita e direta [...]" (SAVIANI, 2008c, p. 39). Para estimular, os trabalhos sindicalizados e seus dependentes, podia ser concedida bolsa de estudo pela União, bolsa que fazia parte do Programa Especial de Bolsas de Estudo - PEBE, instituída pelo Decreto no 57.870, de 25 de fevereiro de 1966, destinada a 
assegurar ensino médio a estudantes que não tinha recursos para financiar seus estudos (SAVIANI, 2008c, p. 39).

O parecer n 11/2000, que trata das Diretrizes Curriculares Nacionais para à educação de jovens e adultos, tem como discurso a expressão do potencial humano com o poder de se qualificar, se requalificar e descobrir novos campos de atuação como realização de si próprio (BRASIL, 2000, p. 11). O ensino supletivo foi regulamentado pela resolução $\mathrm{n}^{\circ}$ 6997, cuja elaboração esteve sob a responsabilidade do extinto Conselho Federal de Educação - CFE, hoje Conselho Nacional de Educação - CNE. Em 1974, o Ministério da Educação e Cultura - MEC, propôs a implantação de Centros de Estudos Supletivos - CES, como a solução mais viável para essa modalidade de ensino, atendendo ao tríplice objetivo de tempo, rapidez de instalação; custo de aproveitamento de espaços ociosos e efetividade com emprego de metodologias adequadas.

No ano de 1985, foi criado a Fundação Educar, com o objetivo de acompanhar e supervisionar as instituições e secretarias que recebiam recursos para executar programas direcionados a educação de adultos. Todavia, a referida fundação foi extinta em 1990, após um período de omissão do governo federal em relação às políticas de alfabetização de jovens e adultos, retornando, somente, com a implementação das premissas trazidas pela Constituição Federal de 1988, na qual o direito à educação para jovens e adultos passou a ser garantido (PAIVA, 1983, p. 139).

A efetivação de uma educação de qualidade e da construção de uma identidade própria da EJA só ocorre na gestão democrática da educação, prevista na Constituição Federal de 1988 e a partir da aprovação da Lei de Diretrizes e Bases da Educação Nacional- LDB, que estabelece em seu artigo $5^{\circ}$ os princípios da modalidade da EJA, no que se refere a equidade, a diferença e a proporcionalidade, tornando este documento fundamental para educação de jovens e adultos, reconhecendo a diversidade cultural e regional existentes nos diversos extratos sociais, já que seus sujeitos são dotados de uma rica bagagem cultural transmitida, principalmente, por meio da oralidade, que deve ser valorizada nesta modalidade da educação básica.

As diretrizes curriculares nacionais para a educação de jovens e adultos funda-se na concepção de que tal modalidade de educação consiste num "modo de existir com característica própria", devendo o seu desenvolvimento considerar "as situações, os perfis dos estudantes, as 
faixas etárias" e se pautar "pelos princípios de equidade, diferença e proporcionalidade na apropriação e contextualização das diretrizes curriculares nacionais e na proposição de um modelo pedagógico próprio", situações que só foram possíveis a partir das questões apresentadas pela LDB, que mobilizou uma discussão nacional para que a EJA se tornasse uma modalidade da educação básica (BRASIL, 2000, p. 2).

Nesse sentido, a EJA deixa de ser considerada como projeto de governo, ou como ações pontuais de alfabetização e elevação de escolaridade, principalmente de ensino fundamental, com o escopo de promover o pleno desenvolvimento da pessoa conforme postulado na Constituição. A LDB assume a educação básica como política pública no sistema nacional de ensino de tal forma que, além da consolidação dos princípios legais da Constituição, a LDB deu visibilidade para o início de discussões sobre como pensar em formas de garantir direitos já conquistados e identificar o papel da educação nos cenários políticos e históricos, para refletir a diversidade dos sujeitos sociais da EJA em prol da ampliação dos direitos sociais e das responsabilidades do Estado no atendimento às necessidades dos grupos sociais mais pobres, àqueles que não completaram o ensino fundamental gratuito adequado à sua condição de jovens e adultos trabalhadores (DI PIERRO; JOIA; RIBEIRO, 2001, p. 66).

A década de 90 foi marcada pela relativização nos planos cultural, jurídico e político dos direitos educativos das pessoas jovens e adultas conquistados em momentos anteriores, bem como a descentralização da problemática proposta e a situação marginal da EJA nas políticas públicas do país, porém, a Lei de Diretrizes e Base da Educação Nacional, em seu artigo 38, faz referência aos cursos e exames supletivos, além de manter a proposta da suplência, de compensação e de correção de escolaridade (HADDAD; DI PIERRO, 2000, p. 121).

A Declaração de Hamburgo sobre a Educação de Adultos, de 1997, resultado da V Conferência Internacional para a Educação de Adultos (CONFINTEA) enfatiza a importância da educação de adultos, como ponto chave para o século XXI, para o exercício da cidadania e a plena participação na sociedade (UNESCO, 1997, p. 1). Mesmo diante do referido contexto propositivo, ressalta-se que a EJA não tem sido incluída como prioridade estatal nas políticas públicas educacionais, esclarecendo-se que tal afirmação se torna clara com a criação do Fundo de Manutenção e Desenvolvimento do Ensino Fundamental e valorização do Magistério FUNDEF, que contava os alunos do ensino fundamental para o retorno dos recursos, ou seja, 
verbas de investimento em educação, que não considerava os alunos da EJA. O afastamento da União nas políticas públicas de EJA, transferindo a responsabilidade para os Estados, o Distrito Federal e os Municípios, proporcionou iniciativas de cunho popular, caracterizando uma pulverização de programas na tentativa de minimizar a problemática de EJA no Brasil (HADDAD; DI PIERRO, 2000, p. 123).

O Estado, mesmo em razão da necessidade de prestar contas à comunidade internacional sobre os índices de analfabetismo, resolver o problema instalado e erradicar o analfabetismo, deixa de priorizar a implementação das políticas voltadas à educação de jovens e adultos, momento em que surgem manifestações populares que se contrapõe a essa postura inerte do ente estatal. Diante dessas premissas apresentadas fica clara a intenção políticogovernamental do Estado, pois torna invisível o público desta modalidade de ensino, o que demonstra as fragilidades nas políticas de governo e a falta de políticas de base para erradicar o analfabetismo no Brasil (FRIEDRICH; BENITE; BENITE; PEREIRA, 2010, p. 400-402).

No ano de 2003 surge o Programa Brasil Alfabetizado - PBA do MEC, voltado para a alfabetização de jovens, adultos e idosos, objetivando o acesso à cidadania e o despertar do interesse pela elevação do nível de escolaridade entre as pessoas. O Programa Brasil Alfabetizado passa a ser desenvolvido em todo o território nacional, com o atendimento prioritário aos municípios que apresentavam alta taxa de analfabetismo, destacando-se que 90\% desses municípios localizam-se na região nordeste. Os respectivos municípios receberam apoio técnico na implementação das ações do programa, visando garantir a continuidade dos estudos, com a finalidade de superar o analfabetismo entre jovens com 15 anos ou mais, adultos e idosos, para contribuir com a universalização do ensino fundamental no Brasil, reconhecendo a educação como direito humano e a oferta pública da alfabetização como porta de entrada para a educação e a escolarização das pessoas ao longo de toda a vida (BRASIL, 2003).

Importante problematizar criticamente essa proposta estatal, que é fundada em metodologias quantitativas, já que a qualidade na formação escolar dessas pessoas não constituiu a prioridade do Estado. Visando atender aos interesses do sistema capitalista, o objetivo precípuo dessa política pública sempre foi qualificar pessoas para atender as demandas do mercado de trabalho, já que o objetivo central proposto pela constituição brasileira de 1988, que é a formação crítica para o exercício da cidadania e o pleno desenvolvimento da pessoa 
humana, não constituiu o anseio imediato do Estado. Outra justificativa utilizada pelo Estado para implementar a referida política pública educacional é o aumento quantitativo do IDH Índice de Desenvolvimento Humano, medido por organismos internacionais a partir do número de pessoas alfabetizadas e que concluíram o ensino fundamental e médio no Brasil.

Ainda nesse contexto propositivo, das políticas públicas desenvolvidas para a EJA, destaca-se, também, os programas voltados à educação de jovens e adultos profissionais, como é o caso do Promovem Campo e o Projovem Urbano, instituídos pela Lei n. ${ }^{\circ} 11.129$, de 30 de junho de 2005, em âmbito nacional. Seu objetivo era o de promover o desenvolvimento e aumento da escolaridade do ensino fundamental com qualificação profissional para a população jovem entre 18 a 29 anos de idade, endossando os apontamentos críticos acima apresentados.

Atualmente os referidos programas são regidos pela Lei $\mathrm{n}^{\circ}$ 11.692, de 10 de junho de 2008, a qual dispõe que o atendimento à população será realizado a partir das modalidades: Projovem Adolescente - Serviço Socioeducativo; Projovem Urbano; Projovem campo Saberes da Terra; Projovem Trabalhador. Em 2005, o Decreto 5.478 de 24 de junho, institui o PROEJA, somente no âmbito das Instituições Federais de Educação. Porém, em 2006, por meio do Decreto $\mathrm{n}^{\circ} 5.840$ de 13 de julho, que revogou o anterior, e do Documento Base deste programa publicado em 2006 pelo MEC, foi possível a ampliação da sua oferta às redes estaduais de educação, ressaltando-se que o respectivo programa passou a ser caracterizado como uma política pública de âmbito nacional (PARANÁ, 2007, p. 12).

O Plano Nacional de Educação 2001-2010 previa erradicação do analfabetismo, garantindo-se que ao menos $50 \%$ (cinquenta por cento) da população com quinze ou mais anos pudessem frequentar o ensino fundamental, com $100 \%$ (cem por cento) de oferta de EJA Educação de Jovens e Adultos aos que, nesta faixa etária, não concluíram os estudos de $5^{\mathrm{a}}$ e $8^{\mathrm{a}}$ série e "quadruplicar a capacidade de atendimento de EJA no ensino médio, em dez anos". Entretanto, estas metas não foram cumpridas, seja por responsabilidade da União, seja pelas responsabilidades do Estados, do Distrito Federal e dos Municípios (AGUIAR, 2010, p. 176).

O Plano Nacional de Educação de 2014, Lei 13.005/2014 (BRASIL, 2014) define metas e estratégias para a oferta de EJA como, por exemplo, que ela seja proporcionada “[...] a todos que não tiveram acesso à educação básica na idade própria”; que se realize “[...] chamadas públicas regulares para educação de jovens e adultos, promovendo-se busca ativa em regime de 
colaboração entre entes federados e em parceria com organizações da sociedade civil"; e que se desenvolvam atendimentos aos estudantes da EJA, como "[...] programas suplementares de transporte, alimentação e saúde, inclusive atendimento oftalmológico e fornecimento gratuito de óculos, em articulação com a área da saúde”. Embora tal política pública tenha sido implementada por meio de legislação federal, é importante esclarecer que todos os entes político-administrativos têm suas cotas na corresponsabilidade para, se não eliminar, ao menos diminuir os problemas educacionais que vivem os sujeitos excluídos socialmente.

\section{ASPECTOS DA EDUCAÇÃO DE JOVENS E ADULTOS NO ESTADO DO PARANÁ}

A problemática jurídica apresentada ao debate no referido item da pesquisa justificase em termos metodológicos em virtude da necessidade de delimitar o espectro de análise e estudo do direito à educação de jovens e adultos especificamente no Estado do Paraná, com o condão de averiguar se as propostas regionais dialogam de forma estreita com as proposições trazidas pela legislação federal. Com a criação do Sistema Estadual de Ensino e do Conselho Estadual de Educação - CEE, o Paraná organizou a legislação que normatizou a abertura de cursos noturnos, bem como sugeriu a elaboração de currículos específicos para a educação de jovens e adultos (BRASIL, 2000, p. 2).

No Estado do Paraná a educação de jovens e adultos passou a fazer parte formalmente da política pública educacional, em fevereiro de 2002, com a criação do Fórum Paranaense de EJA, instância que tornou mais forte a articulação das instituições governamentais, nãogovernamentais, empresariais, acadêmicas e movimentos sociais, em reuniões plenárias regionais e nos Encontros Paranaenses de EJA - EPEJAS. Este movimento nacional e paranaense tem qualificado as proposições, experiências, intercâmbios e avaliações das políticas de educação de jovens e adultos, propiciando iniciativas e esforços para ampliar o direito à educação pública e de qualidade para os educandos que não tiveram acesso à escola ou se afastaram dela em determinado momento de sua vida (PARANÁ, 2006, p. 22). 
O Paraná se destacou por ter sido o primeiro Estado a realizar exames de suplência profissionalizante, a partir de 1977. A política neste momento tinha o objetivo de "[...] atingir um grande número de pessoas já possuidoras de qualificação profissional, a ser reconhecida mediante os referidos exames, ao nível de (sic) $2^{\circ}$ grau", destacando-se que as primeiras habilitações propostas foram de química e de secretariado. A partir de 1980 a Secretaria da Educação do Estado do Paraná passou a oferecer exames de suplência profissionalizante em agricultura, eletrônica, telecomunicações, radiologia médica, patologia clínica e auxiliar de enfermagem. Os últimos exames de suplência foram ofertados na década de 1990, na área de transações imobiliárias, visto que a última etapa ocorreu em outubro de 1994, não podendo deixar de mencionar a formação em auxiliar de enfermagem, cujo último exame foi aplicado em julho de 1998 (CORREIA, 2008, p. 30).

Com as Diretrizes Curriculares da EJA do Paraná, além do ensino supletivo seriado criado na década de 1980, surgiram os Centros de Estudos Supletivos - CES, atualmente denominados Centros Estaduais de Educação Básica para Jovens e Adultos - CEEBJA, e os Núcleos Avançados de Ensino Supletivo - NAES. Tais centros foram uma conquista legal dos estados, inclusive para o Estado do Paraná, que buscava aumentar a capacidade de atendimento da população da EJA, como está previsto na Constituição Federal de 1988 (PARANÁ, 2006, p. 20).

O Conselho Estadual de Educação do Paraná produziu a Deliberação nº 016/95 para educação de jovens e adultos, estabelecendo novas normas para o funcionamento dos CES, mantendo a matrícula por disciplina, o não estabelecimento de carga horária mínima para elas, a idade mínima, anteriormente, dada para ingresso 14 anos para o $1^{\circ}$ grau e 18 anos para o $2^{\circ}$ grau, a reserva de sua oferta apenas à estabelecimentos públicos, e a frequência facultativa para o aluno, renovando, apenas, a oferta de momentos coletivos nos CES (PARANÁ, 1998d, p. $320)$.

Este reordenamento jurídico provocou novas interpretações sobre a modalidade da EJA, como a possibilidade dos CES implantarem o Posto Avançado do CES - PAC, uma forma de atendimento descentralizado que poderia ocorrer apenas para o $1^{\circ}$ grau e nos municípiossede de CES, Núcleos Regionais de Educação e Casas Familiares Rurais, que passou a ser 
possível a implantação desta estrutura em bairros onde não houvesse oferta de Ensino Supletivo (CORREIA, 2008, p. 49).

A CEE publicou a Deliberação no 10 de 1996, que aprovou uma reestruturação dos cursos supletivos, que até então eram seriados. Tais cursos supletivos passaram a ser organizados por blocos de disciplinas, com duração semestral, prevendo atendimento individual de uma hora, com presença facultativa para o aluno e atendimento coletivo, com presença obrigatória. A promoção seria feita por blocos de disciplinas e caso não conseguisse aprovação, o aluno poderia frequentar cursos de férias, que seriam ofertados nos CES (PARANÁ, 2006, p. 19).

Em 1997, a Deliberação n 07 estendeu a possibilidade de implantação do PAC (Posto Avançado do Centro de Estudos Supletivos) aos pequenos municípios onde não havia a oferta de educação de jovens e adultos e também aos postos indígenas e comunidades rurais, que foram explicitadas nas Diretrizes Curriculares Nacionais para a EJA, no ano de 2000. O Conselho Estadual de Educação do Paraná, antecipou às Diretrizes Curriculares Nacionais, com a Deliberação $n^{\circ}$ 012/99, que definiu “'[...] a necessidade de reestruturação das instituições que ofertam educação de jovens e adultos, bem como dar significado operacional ao texto da LDB - Lei no 9.394/96" (PARANÁ, 1999a, p. 10).

A deliberação supracitada, procurou explicitar os elementos que deveriam constituir as propostas pedagógicas dos estabelecimentos que ofertariam EJA, com relação à idade, quais cursos que deveriam ser organizados de forma presencial, com frequência obrigatória de $75 \%$ da carga horária total, ou à distância, conforme legislação em vigor, bem como a carga horária de 3.200 horas para o Ensino Fundamental, sendo 1.300 horas para a Fase I e 1.900 horas para a Fase II, e para o Ensino Médio, com 1.600 horas de efetivo trabalho escolar (CORREIA, 2008, p. 51).

Em 2001 ocorreu migração de muitos alunos para os CEEBJA's (Centro de Educação Básica de Jovens e Adultos), com o objetivo de acelerarem a conclusão do ensino médio e ingressarem no ensino superior, que culminou na edição da Deliberação nº 07/2001, com objetivo de determinar a idade mínima para conclusão do ensino fundamental de 15 anos e para a conclusão do ensino médio, de 18 anos, passando a determinar o aproveitamento de estudos, de séries e disciplinas concluídas por exames, ressaltando-se que só poderia ser realizado 
mediante avaliação que dispensaria o aluno, no máximo, 50\% dos conteúdos e da carga horária a ser cumprida (CORREIA, 2008, p. 52).

De acordo com as Diretrizes Curriculares da EJA do Paraná, em sintonia com o cenário nacional, a Secretaria de Estado da Educação do Paraná - SEED, de 1993 a 2003, financiou ações de alfabetização realizadas em parceria com Organizações Não-Governamentais no Paraná, por meio de dois programas fundamentais para erradicar o analfabetismo no Brasil: o Programa Alfabetização Solidária de 1997 e o Programa Paraná Alfabetizado de 2003, ambos com o escopo de dar continuidade à escolarização na rede estadual de educação, ponto positivo enquanto política pública.

O programa alfabetização solidária manifestava como objetivo reduzir os índices de analfabetismo do país, focalizando nos jovens de 12 a 18 anos. Em 1997, priorizava os municípios com taxas de analfabetismo superiores a 55\%, os localizados nas regiões norte e nordeste e, em 1999, atingiu os grandes centros urbanos, esclarecendo-se que a região centrooeste e sudeste foi palco somente no ano de 2002 (BARREYRO, 2010, p. 176).

Os programas eram realizados mediante as chamadas "parcerias" com empresas que custeavam metade dos gastos por aluno e a outra metade era de responsabilidade dos fundos públicos, advindos do MEC. Contava também com o apoio das universidades, que executavam as ações de alfabetização por meio de coordenadores e de alfabetizadores selecionados e capacitados; aos municípios, ficavam a responsabilidade das questões operacionais como as salas de aula, merenda, convocatórias. Os alfabetizadores eram pessoas do próprio município ou estudantes das universidades que recebiam um curso de capacitação e as aulas eram organizadas em módulos de seis meses de duração cada uma, os alunos e os alfabetizadores podiam participar de um módulo, apenas (BARREYRO, 2010, p. 176).

O Programa Paraná Alfabetizado, no Estado do Paraná, foi coordenado pela Secretaria de Estado da Educação, desenvolvido em parceria com o MEC/SECADI/ Programa Brasil Alfabetizado, Associação dos Municípios do Paraná - AMP, União dos Dirigentes Municipais de Educação no Paraná- UNDIME-PR, Prefeituras Municipais e demais organizações governamentais e da sociedade civil (PARANÁ, 2007-1). Segundo as Diretrizes Curriculares da EJA do Paraná, os cursos da EJA oferecidos pela SEED até o ano de 2005, estavam organizados de maneira presencial e semipresencial. O modo presencial oferecido pela Rede 
Pública Estadual no período noturno e o semipresencial oferecido pelos CEEBJA, sendo 30\% presencial e $70 \%$ não presencial:

\begin{abstract}
Os cursos para jovens e adultos ofertados pela SEED até 2005 se organizavam nas formas presencial e semipresencial. Os cursos presenciais por etapas, na Rede Pública Estadual, eram ofertados exclusivamente no período noturno, na Fase II do Ensino Fundamental. No Nível Médio, eram divididos em quatro etapas, cada uma com a duração de um semestre. Por sua vez, a matrícula era feita por etapa, com avaliação no processo (PARANÁ, 2006, p. 25).
\end{abstract}

A educação de jovens e adultos profissional, como o Projovem Campo e o Projovem Urbano, instituído pela Lei n. ${ }^{\circ} 11.129$, de 30 de junho de 2005, em âmbito nacional, foi executado pelo Governo do Estado do Paraná a partir de 2008 por meio da Secretaria de Estado da Criança e da Juventude - SECJ e regidos pela Resolução/CD/FNDE no 22 de 26 de maio de 2008 e pelo Decreto Estadual n 2.785 de 04/06/2008, tendo sua primeira turma somente no ano de 2009.

Os cursos da EJA, a partir de 2006, passaram a serem organizados somente no modo presencial e a matrícula passou ser realizada por disciplinas de forma individual ou coletiva. A forma coletiva para os educandos que podiam frequentar regularmente as aulas a partir de um cronograma preestabelecido e o modo individual, para os que não podiam frequentar com regularidade (PARANÁ, 2006, p. 25).

Importante esclarecer que o Estado do Paraná utiliza atualmente, como instrumentos de certificação na educação básica, os exames de EJA, tanto para o ensino fundamental, quanto para o ensino médio; o ENCCEJA (Exame Nacional para Certificação de Competências de Jovens e Adultos), para o Ensino Fundamental e o ENEM (Exame Nacional do Ensino Médio), para o Ensino Médio. Os exames de EJA no Paraná são de responsabilidade da SEED/PR, tanto em sua elaboração, quanto na sua implementação, tendo o Projeto Anual dos Exames de EJA analisado pelo Conselho Estadual de Educação do Paraná - CEE/PR, que possui a prerrogativa na LDB e na Deliberação nº 05/10 CEE/PR.

Por meio da Resolução n 1.783/2007 do Conselho Estadual de Educação em 2007, foi estabelecida a realização dos exames supletivos em nível de Fase II do Ensino Fundamental e Ensino Médio, que passariam a ser realizados em duas etapas anuais, uma em junho e outra em novembro. A primeira etapa, ofertada no ensino fundamental Fase II, abarcariam as disciplinas 
de língua portuguesa ${ }^{4}$, língua estrangeira moderna: inglês e ciências. Já o ensino médio, língua portuguesa e literatura, língua estrangeira moderna: inglês, biologia, química, filosofia e sociologia. Na segunda etapa do ensino fundamental fase II, seriam objeto de avaliação as disciplinas de matemática, história e geografia e no ensino médio, matemática, história, geografia e física. Porém, para ser aprovado, o indivíduo deveria obter nota mínima de seis em cada disciplina, caso não atingisse a média podia refazer a prova no ano seguinte.

Por meio do DEJA (Departamento de Educação de Jovens e Adultos), a SEED (Secretaria de Estado de Educação do Paraná) desde o ano de 1999, com autorização do MEC e do Ministério das Relações Exteriores, realizava exames supletivos para brasileiros residentes no Japão, e desde 2006 os exames passaram a ser ofertados para brasileiros em processo de privação de liberdade em uma unidade penitenciaria japonesa e em uma escola de disciplina para adolescentes também no Japão. Em 2005 os exames passaram a ser ofertados para brasileiros residentes na Europa, de forma gratuita, e o ônus financeiro que inclui a organização, aplicação, correção e o deslocamento de funcionários até os países onde serão aplicados os exames ficavam a cargo dos Estados Federados.

O manual de orientações para educação de jovens e adultos, ensino fundamental - Fase II e ensino médio, do ano de 2012, propunha que a educação para estes estudantes deveria ser ofertada de forma coletiva ou individual. $\mathrm{O}$ atendimento coletivo era "preferencialmente" aos que podiam frequentar as aulas sem prejuízo por excesso de faltas e o atendimento individual para àqueles que não poderiam frequentar as aulas com a regularidade exigida (PARANÁ, 2012, p. 3). O plano estadual de educação do Paraná de 2015-2025 apresenta 20 metas, das quais duas são direcionadas a Educação de Jovens e Adultos:

Meta 9: Elevar a taxa de alfabetização da população com 15 anos ou mais para 97\%
e reduzir em $50 \%$ a taxa de analfabetismo funcional até o final da vigência deste Plano.
Meta 10: Oferecer, no mínimo, 25\% das matrículas de Educação de Jovens e Adultos,
na forma integrada à Educação Profissional, nos ensinos Fundamental - Fase II e
Médio (PARANÁ, 2015, p. 81-82).

A partir das premissas apresentadas e discutidas no âmbito da presente pesquisa, tornase relevante esclarecer que o Estado do Paraná tem uma taxa de analfabetismo de 4,5\% para maiores de 15 anos, número inferior à taxa nacional, mas de acordo com a Meta 9 do Plano

\footnotetext{
${ }^{4}$ Nas provas de Língua Portuguesa tanto do Ensino Fundamental quanto do Ensino Médio o candidato é obrigado a fazer uma produção de texto que tem peso 6 e a parte de conhecimentos da língua tem peso 4 .
} 
Estadual de Educação do Paraná de 2015-2025, o Estado articula políticas públicas para que até 2025, este percentual baixe para 3\%, por meio de efetivação de ações concretas, como política de Estado, a serem realizadas em regime de colaboração com a União e os Municípios, para o avanço educacional estadual e na superação das desigualdades historicamente construídas, promovendo uma educação de qualidade para todos os paranaenses, com o fim de diminuir o analfabetismo, por meio de estratégias específicas para este segmento da educação.

Evidencia-se, pelo que fora exposto a partir da pesquisa bibliográfica e documental desenvolvida, que o Estado do Paraná efetivamente implementou política pública de educação para jovens e adultos, priorizando a metodologia quantitativa e qualitativa, visto que sistematizou um projeto cuja avaliação conteudística e a comprovação de presença mínima nas aulas constituem requisitos essenciais para a conclusão de cada ciclo da formação escolar. Nesse sentido, restou comprovada a diminuição do número de pessoas analfabetas e, consequentemente, tal política pública refletiu no aumento do número de pessoas concluindo o ensino fundamental e médio no Estado do Paraná, em cumprimento e observância das diretrizes nacionais propostas pelo Ministério da Educação e Cultura.

\section{EDUCAÇÃO DE JOVENS E ADULTOS E O ACESSO DE QUALIDADE}

Pretende-se discutir no presente item do artigo cientifico a relevância na utilização de uma metodologia qualitativa no que atine à implementação de política pública educacional voltada para jovens e adultos no Brasil. Em razão da crescente industrialização, desenvolvimento tecnológico e a necessidade de qualificação para o mercado de trabalho, faz se necessário uma formação educacional básica que prepare o indivíduo com capacidade, conhecimento e domínio sobre a cultura formal, as necessidades e as demandas da sociedade contemporânea. Em razão disso, a educação passa ter um papel fundamental, por meio de um processo de construção, uma prática na qual os homens vão se construindo ao longo do tempo e da história. Tal demanda, aliada a políticas internacionais ${ }^{5}$ que vinculam a ajuda econômica

\footnotetext{
${ }^{5}$ Previstas por órgãos como ONU, UNESCO e Banco Mundial no intuito de reforçar a identidade nacional e cultural de cada País, fomentando uma cultura de paz e tolerância a nível mundial.
} 
ao cumprimento de metas educacionais e humanitárias, tem exigido do país ações educacionais para a inserção social dos brasileiros evadidos do processo de escolarização regular.

A UNESCO criou as CONFINTEA's (Conferências Internacionais de Educação de Adultos), com a finalidade de tratar do desenvolvimento pleno dos indivíduos que necessitam do ensino na educação de jovens e adultos e priorizar a formação de todos os autores sociais e políticos envolvidos no ensino na EJA. As CONFINTEA's surgiram a partir da primeira metade do século passado e apareceram com objetivo de produzir documento sobre a problemática da educação de jovens e adultos - EJA. Até o momento foram realizadas seis CONFINTEA's, sendo a primeira na Dinamarca e com o escopo de discutir os seguintes pontos: as especificidades da educação de adultos, proporcionando uma educação aberta e voltada para as condições de vidas reais da população, para que a educação de adultos fosse desenvolvida por meio do espírito de tolerância (OLIVEIRA, InfoEscola, 2019).

Na II Conferência, que aconteceu em 1960 em Montreal no Canadá, houve um debate sobre a necessidade de países mais desenvolvidos ajudarem os países em desenvolvimento melhorar a sua aprendizagem e assegurar a jovens e adultos o direito à educação (OLIVEIRA, InfoEscola, 2019). Na III CONFINTEA, realizada na cidade de Tóquio, Japão, no ano de 1972, houve a constatação de que é preciso adotar um conceito mais amplo de educação, momento que em surgem as categorias de ensino escolar e extraescolar, visto que essas modalidades deveriam garantir a educação integral dos indivíduos de todas as idades, já que é através dessa educação que ocorre o desenvolvimento educacional, econômico e cultural dos países, além do pleno desenvolvimento da cada pessoa humana (OLIVEIRA, InfoEscola, 2019).

No ano de 1985, na França, ocorreu a IV CONFINTEA, que tem como ponto mais importante o direito de ler o próprio mundo e proporcionar a cada pessoa condições de escrever a própria história, além ter acesso aos recursos educacionais, desenvolvendo as capacidades individuais e coletivas, ressaltando-se que todos têm direito a uma educação de qualidade (OLIVEIRA, InfoEscola, 2019).

A V Conferência foi realizada em Hamburgo em 1997, porém teve um caráter diferente das outras, pois obteve uma participação significativa de diferentes parceiros, inclusive da sociedade civil. De acordo com os idealizadores da Declaração de Hamburgo, a educação de adultos engloba todo o processo de aprendizagem, formal ou informal, cujas pessoas 
desenvolvem suas habilidades e seu conhecimento. Foi nesta conferência que os participantes reafirmam a importância do desenvolvimento centrado no ser humano e a existência de uma sociedade participativa, baseada no respeito integral aos direitos humanos, para que haja um desenvolvimento justo e sustentável, com a efetiva participação e emancipação de homens e mulheres em cada esfera da vida civil (OLIVEIRA, InfoEscola, 2019).

Em 2009 foi realizado no Brasil, no estado do Pará, na cidade de Belém, a VI Conferência, cujo objetivo foi reavaliar os principias pontos da V conferência e ressaltar a necessidade de criação de instrumentos de advocacia para educação de adultos, além de reafirmar que os compromissos que não foram plenamente assumidos, desde a última Conferência, passasse a ter efetividade e eficácia na educação de jovens e adultos - EJA (OLIVEIRA, InfoEscola, 2019).

A legislação constitucional e infraconstitucional brasileira, aderindo aos ditames e orientações internacionais ora expostas, foi sistematizada no sentido de assegurar simultaneamente o direito de acesso à educação, priorizando-se sua oferta de qualidade, para proporcionar condições às pessoas de alcançar o pleno desenvolvimento, o exercício da cidadania, além da preparação para o mercado de trabalho. A partir dessas premissas, a constituição brasileira de 1988 estabelece, no parágrafo $7^{\circ}$, do artigo 206, "a garantia de qualidade" de ensino; a LDB (Lei de Diretrizes e Base da Educação Nacional) Lei n 9394/96 também o faz no artigo $3^{\circ}$, inciso IX, ao proclamar que “o ensino será ministrado com base nos seguintes princípios [...] garantia de padrão de qualidade"; e no artigo $4^{\circ}$, inciso IX, da mesma lei assegura "padrões mínimos de qualidade de ensino, definidos como a variedades e quantidade mínimos, por estudantes, de insumos indispensáveis ao desenvolvimento do processo de ensino-aprendizagem". Ainda com relação à prioridade do legislador em garantir educação de qualidade, ressalta-se:

[...] essa incorporação não foi suficiente para estabelecer de forma razoavelmente precisa em que consistiria ou quais elementos integrariam o padrão de qualidade do ensino brasileiro, o que dificulta bastante o acionamento da justiça em caso de oferta de ensino com má qualidade. Afinal, como caracterizar um ensino com ou sem qualidade, se não há parâmetros para o julgamento? (OLIVEIRA, 2005, p. 17)

Gadotti, reconhecendo a necessidade de investigar o significado de qualidade para a educação brasileira, principalmente para a modalidade EJA, reconheceu que o conceito abarcava uma forma histórica e dinâmica, e descreveu: 
Quando a escola pública era para poucos, era boa só para esses poucos. Agora que é de todos, principalmente para os mais pobres, ela precisa ser apropriada para esse novo público, ela deve ser de qualidade sociocultural. Isso significa investir nas condições que possibilitam essa nova qualidade, que inclui transporte, saúde, alimentação, vestuário, cultura, esporte e lazer. Não basta matricular os pobres na escola (inclusão). É preciso matricular com eles, também, a sua cultura, os seus desejos, seus sonhos, a vontade de ser mais (FREIRE). É preciso matricular o projeto de vida desses novos alunos numa perspectiva ética, estética e ecopedagógica. A educação integral precisa visar à qualidade sociocultural da educação, que é sinônimo de qualidade integral (GADOTTI, 2010, p. 9).

Gadotti problematiza o debate demonstrando que o acesso à educação, quando reconhecido aos jovens e adultos pobres que não tiveram acesso à educação formal na idade regularmente estabelecida na legislação vigente, deve compreender algo que vai além do direito de se matricular e ter acesso à escola. Por isso propõe que a escola seja um espaço plural, de respeito à diversidade, que priorize a igualdade de tratamento, que preze pelo acolhimento desses alunos, respeitando sua identidade cultural, assegurando-lhes direito à saúde, vestuário, alimentação, esporte, lazer e outras questões peculiares que refletem de forma direta no processo ensino-aprendizagem.

De acordo com Demo, “qualidade aponta para a dimensão da intensidade, tem a ver com profundidade, perfeição, principalmente com participação e criação. Está mais para o ser do que para o ter" (DEMO, 2009, p. 11). Visto que a qualidade está relacionada à ação humana, sempre incontrolável e inconstante, capaz de se sobrepor ao anteriormente fixado, de agir contra os efeitos de um poder totalizante e englobante, qualidade implica participação e compromisso, oportunidade de desenvolver potencialidades e a capacidade de ser sujeito de sua própria ação.

Para isso é importante um trabalho pedagógico, uma educação de qualidade aos jovens e adultos, que tenha a teoria como elemento central, capaz de favorecer a possibilidade da reflexão sobre o real, que leve o jovem e o adulto das classes populares muito mais do que a dominar conteúdos, mas a aprender a se relacionar com o conhecimento de forma ativa, construtiva e criador, reconhecendo suas necessidades, possibilidades e aspirações (FÁVERO; RUMMERT; DE VARGAS, 2019). Nesse sentido, a educação de jovens e adultos deve ultrapassar a esfera da mera instrução escolar formal, tecnicista e dogmática; deve-se priorizar a construção de um espaço escolar dialógico, em que família, sociedade e Estado consigam identificar as necessidades e as prioridades de cada microrregião, para que a escola seja vista como um locus de formação cidadã e transformação social, permitindo-se que esses jovens e adultos sintam-se mais pertencentes e atores de todo esse processo educacional. 
Debater a qualidade do ensino ofertado a jovens e adultos torna-se relevante para demonstrar que a presente temática tem relação direta com os reflexos que esse processo educacional causa na vida desses alunos e no espaço onde vivem e constroem suas histórias. Educação de jovens e adultos que prioriza efetivamente a qualidade é aquela cuja execução do projeto torna a escola um espaço de amplo debate, inclusão, igualdade, diversidade; o conhecimento ultrapassa a esfera da sala de aula e dos muros da escola, para ser utilizado como efetivo instrumento de mudanças sociais. A formação educacional de qualidade deve ter o condão de proporcionar a esses jovens e adultos condições de se tornarem agentes sociais que modificarão o bairro, a comunidade ou a cidade onde residem, evidenciando que todo processo de formação educacional tem duplo papel: atende as demandas individuais, ao preparar o aluno para o mercado do trabalho; volta-se aos interesses coletivos, no momento em que o jovem e o adulto se utilizam da escola como espaço de transformação social do local onde vivem, convivem e constroem suas identidades.

Abordando-se o tema garantia do padrão de qualidade da educação de jovens e adultos, a Resolução CNE/CEB no 3, de 15 de junho de 2012 estabeleceu diretrizes operacionais para a educação de jovens e adultos, levando-se em consideração a atenção ao processo educativo em infraestrutura, gestão, formação, valorização dos profissionais da educação, financiamento, jornada escolar, organização pedagógica, entre outros, priorizando-se o direito a uma educação de qualidade, à qualidade social da educação, à exigibilidade da qualidade social, à qualidade de ensino, à qualidade do processo educativo, ao acesso e à permanência do aluno na escola. Nesse contexto, alguns pontos que podem impactar a qualidade da EJA: a qualidade estabelecida pelos respectivos sistemas, a qualidade dos professores de EJA, a qualidade dos profissionais da educação, a qualidade da gestão, a qualidade das ações que determinam a qualidade esperada na ação educativa (JEFFREY; LEITE, 2016, p. 13).

É necessária a qualificação dos profissionais envolvidos neste processo, com a formação continuada, dentro do contexto educacional contemporâneo, que reflita sobre a necessidade de sala de aula da EJA, como forma de que este espaço se transforme num lugar de aprendizagens significativas, possibilitando aos sujeitos transferir esses saberes para outras situações além da sala de aula (FERRARI, 2009, p. 18). Nessa perspectiva propositiva, verificase que a trajetória da EJA, conforme já abordado, possui faces políticas e sociais muito importantes, com a existência de programas governamentais e iniciativas da sociedade civil, de 
movimentos sociais, associações comunitárias e sindicatos, por exemplo. No entanto, Rummert e Ventura afirmam que:

Tais características, entretanto, não alteram sua marca histórica: ser uma educação política e pedagogicamente frágil, fortemente marcada pelo aligeiramento, destinada, predominantemente, à correção de fluxo e à redução de indicadores de baixa escolaridade e não à efetiva socialização das bases do conhecimento (RUMMERT; VENTURA, 2007, p. 33).

Para acompanhar as discussões empreendidas acerca da EJA no Brasil, sobre as principais demandas e desafios, surgem os Fóruns Estaduais de EJA, provocados pelas discussões preparatórias e posteriores à V Conferência Internacional de Educação de Adultos COFINTEA, realizada em Hamburgo na Alemanha em 1997. A partir de 1999, foram realizados Encontros Nacionais de Educação de Jovens e Adultos - ENEJA, considerado um espaço público de debate sobre os desafios e experiências na educação de jovens e adultos, que agregado a outros fóruns, demais encontros estaduais, as ações da sociedade civil e o poder público, marcam a história da educação de jovens e adultos do Brasil (SOUZA, 2011, p. 53).

Os primeiros encontros confirmaram a desarticulação entre as esferas de poder federal, estadual e municipal, indicando a falta de informações sobre aspectos pedagógicos, financeiros e legais, dirigido por instituições governamentais e não-governamentais, movimentos sociais, sindicatos e educadores que dele participam. Tais encontros surgem como instância deliberativa e espaço de socialização de informações e de formação continuada, visando o fortalecimento dos profissionais para a luta em defesa do direito e da qualidade de atendimento na área da educação de jovens e adultos trabalhadores.

O primeiro ENEJA foi na cidade Rio de Janeiro em 1999, com o tema "Em busca de uma política integrada de EJA: articulando atores e definindo responsabilidades”, seguido por Campina Grande, na Paraíba, em 2000 com o tema “O conceito de alfabetização e de parcerias; o terceiro em São Paulo, em 2001, com ênfase em "Plano Nacional de Educação: a quem cabe cumprir?"; o quarto em Belo Horizonte, Minas Gerais - 2002, onde se discutiu "Cenários em mudança"; o quinto em Cuiabá, Mato Grosso, em 2003 com "Educação de Jovens e Adultos: comprometimento e continuidade"; o sexto em Porto Alegre, Rio Grande do Sul, em 2004 sobre "Políticas públicas atuais para a EJA: financiamento, alfabetização e continuidade"; o sétimo em Luziânia, Goiás, em 2005 que enfatizou "Diversidade na EJA: o papel do Estado e dos movimentos sociais nas políticas públicas”. Em 2006 ocorreu oitavo em Recife, Pernambuco, 
com o tema "EJA - uma política de Estado: avaliação e perspectivas"; 2007 ocorre a nona, em Faxinal do Céu, no Paraná, sobre "A atualidade do pensamento de Paulo Freire e as políticas de Educação de Jovens e Adultos no Brasil"; no ano de 2008 na cidade Rio das Ostras, no Rio de Janeiro realiza o décimo ENEJA, com o tema "História e memória dos Encontros Nacionais dos Fóruns de EJA no Brasil: dez anos de luta pelo direito à educação de qualidade social para todos" (BRASIL, ENEJA's, 2019).

A décima primeira, em 2009, foi em Belém, no Pará, sobre "Identidades dos Fóruns de EJA: conquistas, desafios e estratégias de lutas"; em 2011 em Salvador, na Bahia, ocorre a décima segunda, com o tema “A Educação de Jovens e Adultos pós CONFINTEA VI: avanços, desafios e estratégias de lutas"; em 2013, Natal, Rio Grande do Norte, foi realizada o décimo terceiro ENEJA, que tratou sobre” Políticas Públicas em EJA: conquistas, comprometimentos e esquecimentos"; a décima quarta foi realizada em Goiânia, Goiás, em 2015, com a discussão sobre "Concepções de educação popular e suas interconexões com a EJA", e a décima quinta, no ano de 2017 foi em Petrolina no estado de Pernambuco, com o tema "EJA na atual conjuntura política, econômica e social: desafios e possibilidade de luta” (BRASIL, ENEJA's, 2019). O décimo sexto ENEJA será em Belo Horizonte, Minas Gerais, no ano de 2019.

Os Encontros Nacionais de Educação de Jovens e Adultos - ENEJAs, têm a finalidade de defender políticas públicas mais democráticas, que assegurem o direito à educação de jovens e adultos, constitucionalmente conquistado, mas ainda demarcador, pela interdição, da desigualdade que aparta, segrega e produz a iniquidade social para milhões de homens e mulheres que não tem acesso à escola.

Num movimento de transformação social e de produção que visa a melhoria da qualidade de vida, a globalização pasteuriza os comportamentos e as aspirações humanas, exigindo novos conceitos em termos de eficiência da organização de produção, do modelo de gestão, de perfis de qualificação dos padrões de inversão, das vantagens competitivas, os quais a educação de jovens e adultos não tem atingido. Essas novas formas organizacionais são caracterizadas pelo aumento da flexibilidade, com redução de custos e o melhoramento da qualidade da produção e no controle de materiais, que resultam em ganhos significativos de produtividade (RIBEIRO, 2003, p. 227). 
Nesse cenário de debate da problemática cientifica apresentada, a sociedade vive um grande desafio, que é enfrentar os altos índices de desemprego, que afeta, inclusive os países ditos de primeiro mundo, onde a empregabilidade ganhou espaço e centralidade a partir dos anos de 1990, sendo definida como o eixo fundamental de um conjunto de políticas supostamente destinadas a diminuir os riscos sociais do grande tormento do final do século, o desemprego, desigualdades e miséria social (GENTILI, 2005, p. 52).

A educação de jovens e adultos deve ser vinculada à realidade econômica e sociocultural dos indivíduos, ligando ensino e ação transformadora da realidade, ação e reflexão, prática e teoria, pois o conhecimento deve estar comprometido com a emancipação das pessoas, com a liberdade intelectual e política, no qual a educação tem a função da formação cultural e difusão do conhecimento científico, para a formação de sujeitos pensantes e críticos. O ensino deve proporcionar condições para o desenvolvimento da capacidade do sujeito, para colocar-se ante a realidade, a fim de pensá-la e nela atuar, visando à transformação.

Assim, o processo educativo deve ser visto como atividade humana transformadora, como elemento definidor da existência humana, base da sociabilidade humana. Apesar das conquistas no âmbito da educação básica, educação de jovens e adultos (EJA), continua transitando nas margens da educação, ocupando um lugar de pouco valor, uma educação que ao invés de incluir, trata de excluir os indivíduos, devido o lugar social dos sujeitos aos quais se destina. Mesmo diante desse cenário, é importante esclarecer que o planejamento e a execução de políticas públicas educacionais voltadas à formação de jovens e adultos tem o condão de retirá-los do espaço onde vivem, cuja marginalidade e exclusão são naturalizadas para, assim, proporcionar-lhes novos olhares, habilidades e competências, tornando-os mais aptos a construir com autonomia sua própria história e condição cidadã numa sociedade cujo discurso prevalente é a desigualdade em razão de condições socioeconômicas. 


\section{CONCLUSÃO}

A implementação de políticas públicas educacionais para jovens e adultos constitui um meio de assegurar a efetivação do direito fundamental à educação àqueles sujeitos que não tiveram a oportunidade de concluir o ciclo escolar na idade previamente instituída pela legislação brasileira vigente. Importante esclarecer que dentre as razões que explicam os motivos que levaram jovens e adultos interromperem o ciclo regular de formação escolar estão a desigualdade social, a necessidade de ingressar precocemente no mercado de trabalho para manter a si e sua família.

O texto constitucional e a lei de diretrizes e base para a educação nacional preveem expressamente o direito de jovens e adultos terem acesso à escola como meio de tornar viável a conclusão de sua formação escolar. Para isso, o Estado brasileiro, seguindo as orientações propostas por organismos internacionais, como a UNESCO, deve planejar e executar um modelo de política pública educacional que venha a se adequar à realidade vivenciada por esses jovens e adultos, de modo a possibilitar que os mesmos voltem a frequentar a escola.

A compreensão das peculiaridades da microrregião onde será oferecida a educação de jovens e adultos; o diálogo estreito que deve ser construído entre sociedade, Estado e família; a valorização das experiências de vida dos alunos; o oferecimento de modalidades de ensino que sejam acessíveis e viáveis à realidade vivenciada pelos alunos; o planejamento de metodologias que sejam hábeis a trabalhar habilidades e competências dos alunos, levando-se em consideração o ambiente onde os mesmos se encontram inseridos, são algumas das proposições que devem ser levadas em consideração como meio de tornar a escola um ambiente de acolhimento, formação cidadã, preparação para o mercado de trabalho e construção do pleno desenvolvimento da pessoa humana.

Nesse contexto propositivo, verifica-se que o Estado do Paraná planejou, executou e efetivou política pública de educação para jovens e adultos, diminuindo os índices de analfabetismo, aumentando em termos quantitativos o número de pessoas jovens e adultas concluintes do ensino fundamental e médio. Tal política pública adotou a metodologia e as proposições legislativas trazidas pelo texto constitucional e pela legislação federal, 
demonstrando-se que com vontade política, envolvimento de organizações governamentais e não-governamentais, participação da sociedade civil, torna-se viável executar uma política educacional que assegure a inclusão, igualdade de acesso à escola, formação cidadã e preparação para o mercado de trabalho, para aqueles sujeitos naturalmente excluídos desse processo em razão que questões socioeconômicas.

Ao longo do presente estudo buscou-se analisar a política pública que assegure o direito ao acesso à educação básica, especificamente na modalidade da educação de jovens e adultos, como políticas públicas que articulam o efetivo exercício da igualdade, dimensão capaz de possibilitar um alcance da justiça social e reconhecer a educação como direito da personalidade. Analisou-se, também, o fato de o direito à educação ser reconhecido na constituição brasileira de 1988 como um direito social, fundamental para o desenvolvimento pleno de cada cidadão, porém no contexto atual há uma necessidade em ressaltar a importância de a educação como direito fundamental, inerente ao ser humano, inserido no campo dos direitos da personalidade, para o acesso voltado para estudantes oriundos de famílias de baixo poder aquisitivo e reduzido capital cultural.

Verifica-se que todos os entes político-administrativos têm suas cotas na corresponsabilidade para, se não eliminar, ao menos diminuir os problemas educacionais que vivem os sujeitos excluídos socialmente. Não se pode esperar que, somente por meio da educação, resolvam-se estas disparidades (idade-série). É necessário equacionar os problemas sociais, de sustentabilidade da maioria da população, que é composta de trabalhadores assalariados e desempregados. E o Brasil está longe de consolidar isso, portanto, a EJA, como forma de superação do "tempo negado" quanto à escolarização, é uma modalidade que perdurará por muito tempo ainda. No Paraná a educação de jovens e adultos sempre procurou atender e respeitar as especificidades dos adolescentes, dos jovens, dos adultos e dos idosos que buscam dar continuidade em seus estudos interrompidos durante o transcorrer de suas vidas.

$\mathrm{Na}$ formação escolar de jovens e adultos a educação deve ser vinculada à realidade econômica e sociocultural dos indivíduos, ligando ensino e ação transformadora da realidade, ação e reflexão, prática e teoria, visto que o conhecimento está comprometido com a emancipação das pessoas, com a liberdade intelectual e política, no qual a educação tem a função da formação cultural e difusão do conhecimento científico, para a formação de sujeitos 
pensantes e críticos. Um processo educativo como atividade humana transformadora, como elemento definidor da existência humana, base da sociabilidade humana, torna as pessoas mais sujeitos de direito, descoisificando-as e rompendo com a naturalização da marginalidade e exclusão a qual se encontram inseridas.

\section{REFERÊNCIAS}

AGUIAR, Márcia Angela da S. Avaliação do Plano Nacional de Educação 2001-2009: questões para reflexão. Educ. Soc., Campinas, v. 31, n. 112, p. 707-727, jul.-set. 2010.

BARREYRO, Gladys Beatriz. Programa Alfabetização Solidária": terceirização no contexto da Reforma do Estado. Educar em Revista, Curitiba, Brasil, n. 38, p. 175-191, set./dez. 2010. Editora UFPR.

BRASIL. Constituição da República Federativa do Brasil de 1988. Brasília: Senado Federal, Centro Gráfico, 1988.

BRASIL. Congresso Nacional. Lei Federal nº 9.394 de 20 de dezembro de 1996. Estabelece as Diretrizes e Bases da Educação Nacional. Diário Oficial da República Federativa do Brasil, Brasília, DF, 20 dez. 1996.

BRASIL. Conselho Nacional de Educação. Resolução CNE/CEB no 3 de 2010. Dispõe sobre Diretrizes Operacionais para a Educação de Jovens e Adultos. Brasília, DF: CNE, 2000.

BRASIL. ENEJA's. Disponível em http://forumeja.org.br/book/export/html/966. Acesso em 15 jul. 2019.

BRASIL. Ministério da Educação. Programa Brasil Alfabetizado - PBA. Documento Base. Brasília, 2003.

BRASIL. Emenda Constitucional n. ${ }^{\circ}$ 53, de 19 de dezembro de 2006. Presidência da República. Brasília, DF, 2006.

BRASIL. Lei $\mathrm{n}^{\circ}$ 13.005, de 25 de junho de 2014. Aprova o Plano Nacional de Educação (PNE) e dá outras providências. Diário Oficial da União [da] República Federativa do Brasil, Brasília, 26 jun. 2014.

BUCCI, Maria Paula Dallari. O conceito de política pública em direito. In: BUCCI, Maria Paula Dallari. Políticas públicas: reflexões sobre o conceito jurídico. São Paulo: Saraiva, 2006. 
CORREIA, Jorge Luiz. A Política Pública para a Educação de Jovens e Adultos no Paraná (1995-2002). 178f. Dissertação (Mestrado em Educação) - Universidade Estadual de Maringá. Maringá, Paraná, 2008.

DEMO, Pedro. Educação e Qualidade. São Paulo: Papirus, 2009.

DI PIERRO, Maria Clara; JOIA, Orlando; RIBEIRO, Vera Masagão. Visões da Educação de Jovens e Adultos no Brasil. In: Cadernos Cedes, ano XXI, nº 55, novembro, 2001.

FÁVERO, Osmar, RUMMERT, Sônia Maria e DE VARGAS, Sônia Maria. Formação de Profissionais para a Educação de Jovens e Adultos Trabalhadores. Disponível em http://www. forumeja.org.br/gt18. Acesso em: 21 jan. 2019.

FERRARI, Sonia Maria Souza. A Percepção dos Educadores da EJA sobre as Dificuldades de Aprendizagem dos seus Educandos. Trabalho de Conclusão de Curso - Especialização em Educação de Jovens e Adultos da Faculdade de Educação- Universidade Estadual de Campinas - UNICAMP, 2009.

FRIEDRICH, Márcia; BENITE, Anna M. Canavarro; BENITE, Claudio R. Machado PEREIRA, Viviane Soares. Trajetória da Escolarização de jovens e adultos no Brasil: de plataforma de governo a propostas pedagógicas esvaziadas. Ensaio: aval. pol. públ. Educ., Rio de Janeiro, v. 18, n. 67, p. 389-410, abr./jun. 2010.

GADOTTI, Moacir. Qualidade na educação: uma nova abordagem. São Paulo: Editora e Livraria Instituto Paulo Freire, 2010.

GENTILI, Pablo. Três Teses Sobre a Relação trabalho e Educação em Tempos Neoliberais In: LOMBARDI, José; SAVIANI, Dermeval; SANFELICE, José. (Org.). Capitalismo, Trabalho e Educação. 3. ed. - Campinas, SP: Autores Associados, 2005.

HADDAD, Sérgio e DI PIERRO, Maria Clara. Escolarização de Jovens e Adultos. Revista Brasileira de Educação, São Paulo, n.14, p.108-130, mai-ago. 2000.

JEFFREY, Debora Cristina; LEITE, Sandra Fernandes. Qualidade de ensino na modalidade EJA sob a ótica dos docentes. Olh@res, Guarulhos, v. 4, n. 1, p. 8-26, maio 2016.

JULIÃO, Elionaldo Fernandes; VIEIRA, Hellen Jannisy; FERRARI, Beiral Gláucia Maria. As Políticas de Educação de Jovens e Adultos na Atualidade como Desdobramento da Constituição e da LDB. Unisul, Tubarão, v. 11, n. 19, p. 40 - 57, Jan/Jun., 2017.

NASCIMENTO, Juliane do. X CONGRESSO NACIONAL DE EDUCAÇÃO - EDUCER. A educação de jovens e adultos no brasil: a problemática da alfabetização no país. PUC - Curitiba, 2011.

OLIVEIRA, Romualdo Portela de. Gestão financiamento e Direito à Educação. Xamã VM Editora e Gráfica, São Paulo, 2002. 
OLIVEIRA, Emanuelle. Conferências Internacionais de Educação de Adultos (CONFITEA). InfoEscola. Disponível em https://www.infoescola.com/educacao/conferencias-internacionaisde-educacao-de-adultos-confinteal. Acesso em 14 jul. 2019.

PARANÁ. Conselho Estadual de Educação. Deliberação 007/97. Curitiba: 1997a.

PARANÁ. Conselho Estadual de Educação. Superintendência de Educação - Estrutura e Funcionamento da Educação Básica: Educação Infantil, Ensino Fundamental e Ensino Médio. Deliberação 016/95. In: Legislação da Educação Básica. Coletânea VII. Curitiba: 1998d.

PARANÁ; Secretaria de Estado da Educação do Paraná - Departamento da Diversidade Coordenação de Alfabetização de Jovens, Adultos e Idosos -Programa Paraná Alfabetizado.

PARANÁ. Secretaria de Estado da Educação. Diretrizes Curriculares da Educação de Jovens e Adultos. Curitiba, 2006.

PARANÁ. Constituição (1989). Constituição do Estado do Paraná. Curitiba: Imprensa Oficial, 2006.

PARANÁ. Secretaria de Estado da Educação Superintendência da Educação de Departamento de Educação. Diretrizes Curriculares da Educação de Jovens e Adultos. Curitiba, 2006.

PARANÁ, Secretaria de Educação à Distância/Departamento de Educação e Trabalho. Profissional Integrada à Educação de Jovens e adultos. Documento orientador. Versão preliminar. Curitiba-PR, 2007.

PARANÁ. Secretaria de Estado da Educação Superintendência da Educação de Departamento de Educação Básica Coordenação da Educação de Jovens e Adultos. Manual de Orientações Educação de Jovens e Adultos - EJA Ensino Fundamental - Fase II e Ensino Médio. Curitiba: Secretaria de Estado da Educação, 2012.

PARANÁ. Plano Estadual de Educação do Paraná de 2015-2025. Curitiba: Secretaria de Estado da Educação, 2015.

PAIVA, Vanilda Pereira. Painel: Reestruturação Produtiva, Emprego e Qualificação Profissional. Anais do 10. Congresso Estadual de Qualificação. Educação Profissional, Emprego e Renda. Salvador, 10-21 de nov. p. 46-53. 1997.

RIBEIRO, João. Globalização, Mercado de Trabalho e Educação. Revista de Ciências da Educação, Lorena: Centro Unisal, ano 5, n.8, jun. 2003.

RUMMERT, Sonia Maria; VENTURA, Jaqueline Pereira. Políticas públicas para educação de jovens e adultos no Brasil: a permanente (re)construção da subalternidade - considerações sobre os Programas Brasil Alfabetizado e Fazendo Escola. Educar, Curitiba, n. 29, p. 29-45, Editora UFPR,2007. 
SAVIANI, Demerval. A nova lei da educação: trajetória, limites e perspectivas. 11. ed. Campinas: Autores Associados, 2008c, Coleção educação contemporânea.

SOUZA, Maria Antônia de. Educação de Jovens e Adultos. 2. ed. Curitiba: Ibpex, 2011.

UNESCO. Declaração de Hamburgo sobre a educação de adultos e plano de ação para o futuro. In: CONFERÊNCIA INTERNACIONAL SOBRE A EDUCAÇÃO DE ADULTOS, 1997, Hamburgo. Anais... Hamburgo, Alemanha, 1997.

VIEIRA, Edna Ferreira da Costa. Evasão escolar no curso do programa nacional de integração da educação profissional com a educação básica na modalidade de educação de jovens e adultos - PROEJA. Dissertação: Universidade federal Rural do Rio de Janeiro. Instituto de Agronomia, 2009.

ZANETTI, Maria Aparecida. Educação de jovens e adultos na empresa: "novos" e "velhos" olhares se entrecruzam - um estudo de caso de uma empresa metal mecânica que oferece escolarização básica para os seus trabalhadores. 1998. Dissertação de Mestrado. Universidade Federal do Paraná. Curitiba.

Submetido em: 15/07/2019

Aceito em: 18/10/2019 